\title{
Bronchioloalveolar carcinoma: computed tomography findings
}

\author{
J-P. Trigaux*, P.A. Gevenois+*, L. Goncette+, F. Gouat**, \\ A. Schumaker*, P. Weynants++
}

Bronchioloalveolar carcinoma: computed tomography findings. J-P. Trigaux, P.A. Gevenois, L. Goncette, F. Gouat, A. Schumaker, P. Weynants. CERS Journals Ltd 1996. ABSTRACT: The aim of the present study was to investigate the appearance of bronchioloalveolar lung carcinoma on computed tomography (CT) scans, and to determine the frequency of signs suggestive of this diagnosis.

CT features of 42 cases with pathologically proven bronchioloalveolar carcinoma were retrospectively analysed for pattern, size, location and secondary signs suggesting the diagnosis.

Bronchioloalveolar carcinoma had one of the following patterns: solitary nodule or mass (16), lobar consolidation (10), multilobar consolidations (13) and diffuse nodules (3). The 16 solitary nodules or masses ranged in size from 2.0 to $9.4 \mathrm{~cm}$ $($ mean \pm SD $3.75 \pm 1.7 \mathrm{~cm})$. Eleven of the 16 nodules or masses were peripheral and five were central: Eight of the $\mathbf{1 6}$ tumours had pleural tags, seven had spiculated margins, and three had bubblelike lucencies. The consolidations were peripherally distributed in 13 out of 23 cases; cystic airspaces were observed in 19 out of 23 consolidations; bulging of interlobar fissures in 8 out of 23; and the angiogram sign in 7 out of 23 .

In conclusion, computed tomography findings of bronchioloalveolar carcinoma have a wide spectrum, showing typically a peripheral nodule or consolidation. Computed tomography has a role in the diagnosis of nodular localized versus other forms, with subsequent therapeutic and prognostic implications.

Eur Respir J., 1996, 9, 11-16.

\author{
*Dept of Radiology, Hôpital de Mont-Godi- \\ nne, Yvoir, Belgium. **Dept of Radio- \\ logy, Hôpital Erasme, Université Libre de \\ Bruxelles, Brussels, Belgium. +Dept of \\ Radiology, Cliniques Saint-Luc, Université \\ Catholique de Louvain, Brussels, Belgium. \\ ++Dept of Pneumology, Hôpital de Mont- \\ Godinne, Université Catholique de Louvain, \\ Yvoir, Belgium. \\ Correspondence: J-P. Trigaux \\ Dept of Radiology \\ Hôpital de Mont-Godinne \\ B-5530 Yvoir \\ Belgium
}

Keywords: Bronchioloalveolar carcinoma computed tomography diagnosis

lung

lung neoplasms

pulmonary adenocarcinoma

Received: March 111995

Accepted after revision September 251995
Bronchioloalveolar carcinoma (BAC) has varied growth patterns, mixed histological features, and confusing clinical manifestations and evolution [1-8]. Histopathologically, it is classified as a subtype of adenocarcinoma and is characterized by its tendency to spread locally, using the lung structure as stroma, without destroying the underlying architecture [4-6, 9]. Some of the distinguishing pathologic and epidemiological features of BAC include: peripheral location $[10,11]$; association with desmoplastic reaction (scarring) [12]; mucin production [13, $14]$; high occurrence $(30 \%)$ in nonsmokers $[15,16]$; comparatively high female-to-male ratio (1:1 versus $1: 3$ for all other cell types of lung cancer) [17]; and tendency to appear in multiple foci $[18,19]$. Furthermore, recent evidence suggests that adenocarcinoma of the lung has increased in the last decade, and that this overall increase in adenocarcinoma is largely due to an increase in BAC [20].

The spectrum of the radiographic findings is broad with typically three different patterns: 1) a solitary nodule or mass; 2) a localized consolidation; and 3) a multicentric or diffuse disease [21,22]. Various CT patterns suggestive of BAC have recently been reported. These appearances include: cystic air spaces [7, 23]; star pattern and pleural tag reflecting the tendency for the tumour to retract $[7,10,19,21,23]$; the angiogram sign [24]; and bulging of fissures [22]. The frequency of these signs has not been evaluated in sufficiently large samples of patients. The aim of the present study was, thus, to determine their frequencies in 42 consecutive patients with histopathologically proven BAC.

\section{Material and methods}

\section{Study subjects}

We retrospectively reviewed the tumour registry and the CT records of three tertiary-care hospitals over a 4 year period, from 1990 to 1994 , and found 42 patients with pathologically proven BAC (31 males and 11 females; aged 42-80 yrs, mean age $61 \mathrm{yrs}$ ). The diagnosis of BAC was based on the examination of surgical specimens in 24 of the 42 patients and on histological biopsies obtained by transbronchial or transthoracic biopsies in 18. As a rule, in the three hospitals concerned, the diagnosis of bronchioloalveolar carcinoma was made by 
consensus between two observers, at least one trained pathologist and one 2nd year pathology resident. Cases were excluded if a primary adenocarcinoma was present elsewhere, or if a history of treatment for adenocarcinoma was found in the clinical data [4]. The pathological designation of bronchioloalveolar carcinoma was based on the usually accepted criteria of a characteristic appearance of tumour cells, either columnar or cuboidal, growing along the alveolar walls, with preservation of the normal underlying architecture [4]. Smoking habits of the patients were recorded, but in 11 of the 42 patients no pertinent information could be obtained due to the retrospective nature of our study; 10 out of 31 patients were nonsmokers, and 21 of the 31 patients were heavy smokers (range 3-90 pack-yrs; mean 41 20 pack-yrs).

\section{Methods}

In all cases, conventional CT scans were obtained with contiguous sections of 10 or $8 \mathrm{~mm}$ collimation, covering the entire thorax; contrast medium was used in 37 of the 42 cases. In 9 of the 42 cases, high-resolution CT (HRCT) scans were also available (noncontiguous scans of $1 \mathrm{~mm}$ collimation, reconstructed with a highspatial frequency algorithm).

\section{Analysis}

Tumour size was recorded as the average of the maximum craniocaudal, anteroposterior and transverse dimensions. Tumour location was described in terms of the affected lobe(s) and of central versus peripheral location. Peripheral tumours were defined as those that involved the outer third of the lung.

For the nodular form, morphology was defined as smooth or spiculated; the presence of pleural tags and of bubblelike lucencies within the mass was recorded. Pleural tags are triangular strands or projections radiating out from the mass towards the pleural surface [11]. Bubblelike lucencies are sometimes referred to as pseudocavitation, and correspond to patent small bronchi or air-containing cystic spaces inside the nodule.

For the consolidated form, the presence of fissural bulging, of air bronchogram or cystic airspaces within the consolidation, and of an angiogram sign were recorded. The angiogram sign [24] describes a consolidated area of the lung of homogenous low attenuation, within which branching pulmonary vessels are enhanced. For both forms, an invasion of the chest wall, the presence of pleural fluid, and of enlarged lymph nodes (short axis $>1 \mathrm{~cm}$ ) were recorded. Additional radiological findings, including scar fibrosis, and pneumoconiosis were noted. Follow-up data from the medical records were reviewed.

\section{Results}

The four previously described patterns were found: solitary nodule or mass; lobar consolidation; multilobar consolidations; and diffuse nodules. In our series, the prevalences of these patterns were, 16, 10, 13, and 3 out of 42 , respectively. The multifocal nature of BAC consisting in multilobar consolidations and diffuse nodules was, thus, present in 16 out of 42 of our cases: the disease was unilateral in seven patients and bilateral in nine. In 11 isolated forms, the patient's evolution suggested that a continuum exists from the solitary nodule or the lobar consolidation to the diffuse forms (fig. 1). The patient's survival was related to the initial radiological pattern; with a 2 year survival after lobectomy or pneumonectomy of 9 out of 9 for a solitary nodule, and of 0 out of 5 for a localized consolidation.

a)

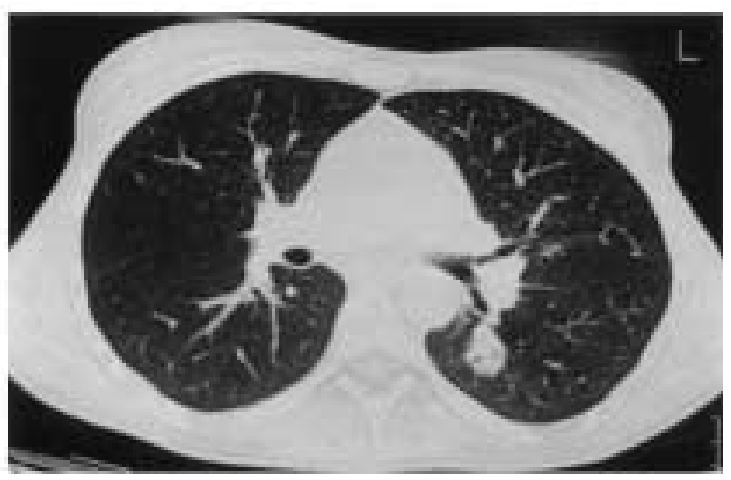

b)

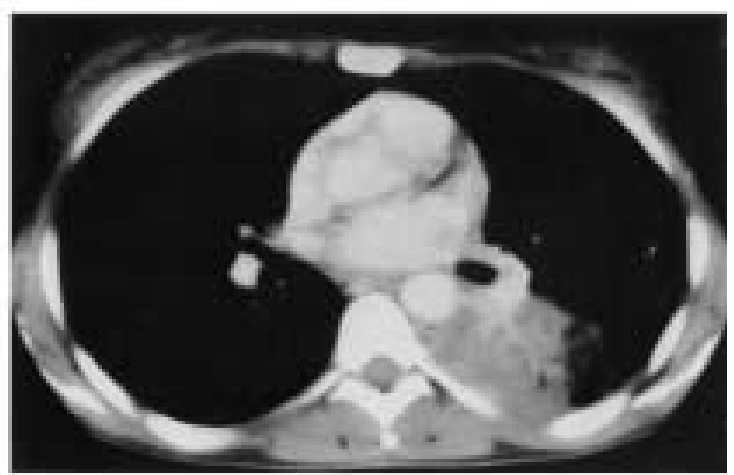

c)

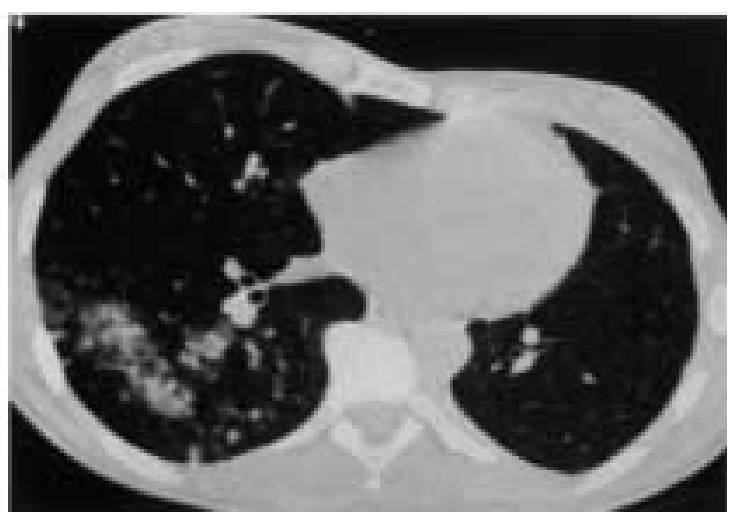

Fig. 1. - Continuum of lesions in the same patient. a) Solitary nodule, $2 \mathrm{~cm}$ in size, localized in the apical segment of the left lower lobe; note bubblelike lucencies inside the nodule. b) Isolated lobar consolidation in the apical segment of the left lower lobe, 15 months later; note the angiogram sign inside the consolidation. c) Controlateral consolidation in the right lower lobe, 4 months later, after left lower lobectomy. 
The size of the 16 solitary nodules or masses ranged $2.0-9.4 \mathrm{~cm}$ (mean $\pm \mathrm{sD} 3.75 \pm 1.7 \mathrm{~cm}$ ); seven tumours were located in the left upper lobe, six in the right upper lobe, two in the right lower lobe, and one in the right middle lobe. Eleven tumours were peripheral. Mediastinal enlarged lymph nodes were present in two patients; one patient had pleural effusion. Seven tumours had spiculated margins, and eight tumours had pleural tags (fig. 2). One tumour showed punctate eccentric calcifications. No chest wall invasion was observed. Bubblelike lucencies inside the nodule was seen in three cases (fig. 3), and overt cavitation in one case (table 1). A widespread multinodular pattern was seen in three patients: in one patient, foci of calcifications were observed in some nodules (fig. 4); in another patient, some nodules were cavitated (fig. 5).

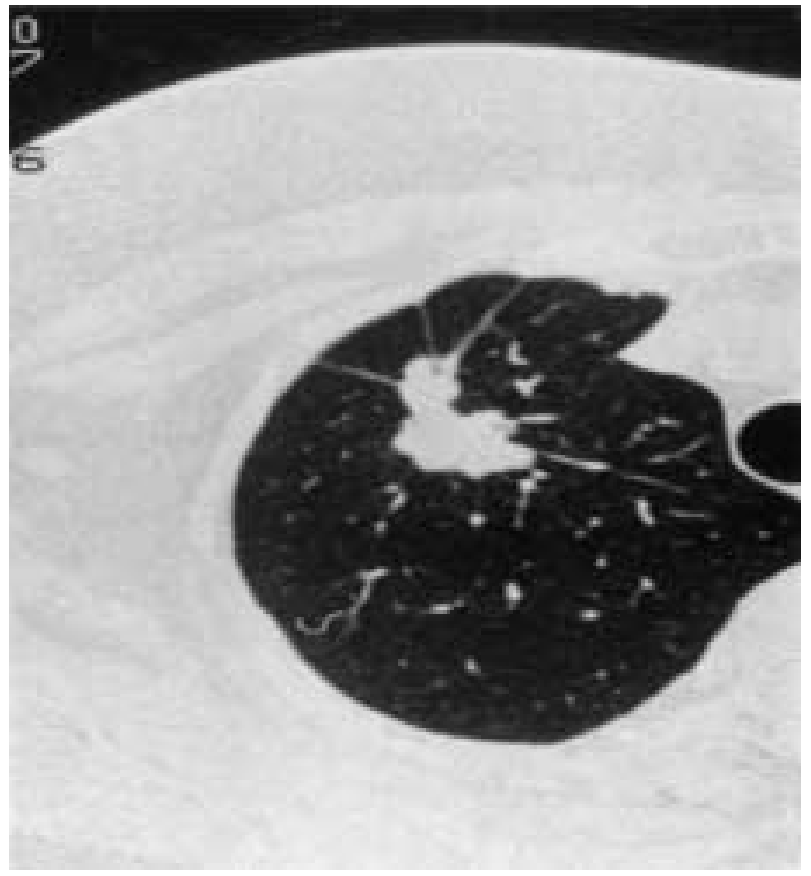

Fig. 2. - Solitary peripheral nodule with pleural tags.

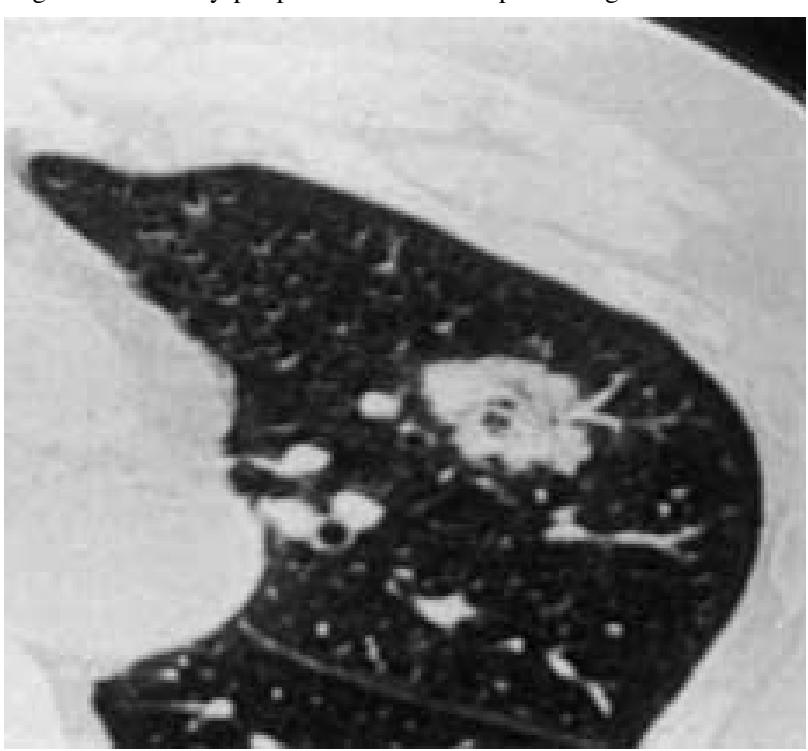

Fig. 3. - Solitary peripheral nodule with bubblelike lucencies.
Table 1. - Typical findings of solitary nodules

$\begin{array}{lr}\text { Peripheral location } & 11 / 16 \\ \text { Pleural tags } & 8 / 16 \\ \text { Spiculated margins } & 7 / 16 \\ \text { Bubblelike lucencies } & 3 / 16 \\ \text { Nodes } & 2 / 16 \\ \text { Pleural effusion } & 1 / 16 \\ \text { Cavitation } & 1 / 16 \\ \text { Calcifications } & 1 / 16 \\ \text { Wall invasion } & 0 / 16\end{array}$

Isolated lobar consolidation was found in 10 patients and multilobar consolidations in 13. Lobar consolidations were located in the right lower lobe in seven cases, in the right upper lobe in two, and in the left lower lobe in one. A peripheral distribution of the consolidations was observed in 13 out of 23 cases. Mediastinal and/or hilar nodes were seen in six patients, and pleural effusion in one. Bulging of interlobar fissures (fig. 6) was observed in 8 out of 23 patients. Cystic air spaces (fig. 6) were apparent in 19 out of 23 patients and air bronchogram in 9 out of 23 patients. An angiogram sign (fig. 7) was seen in 7 out of 23 consolidations (table 2).

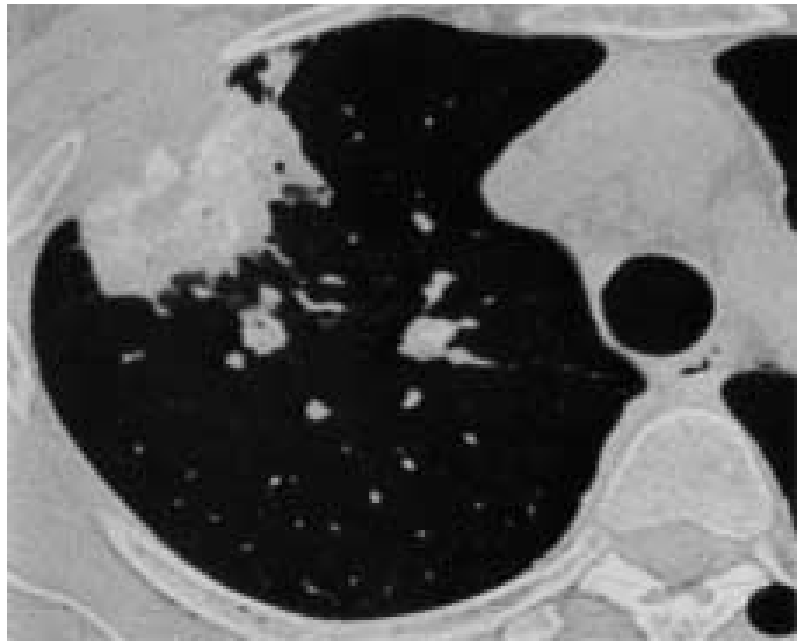

Fig. 4. - Multinodular pattern with foci of calcifications within one of the nodules.

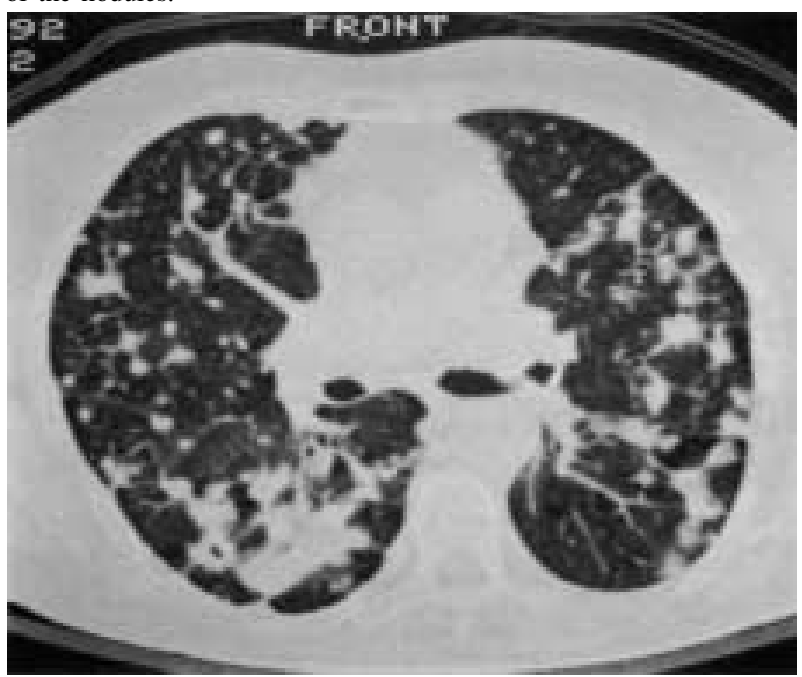

Fig. 5. - Multinodular pattern with cavitation of some nodules. 


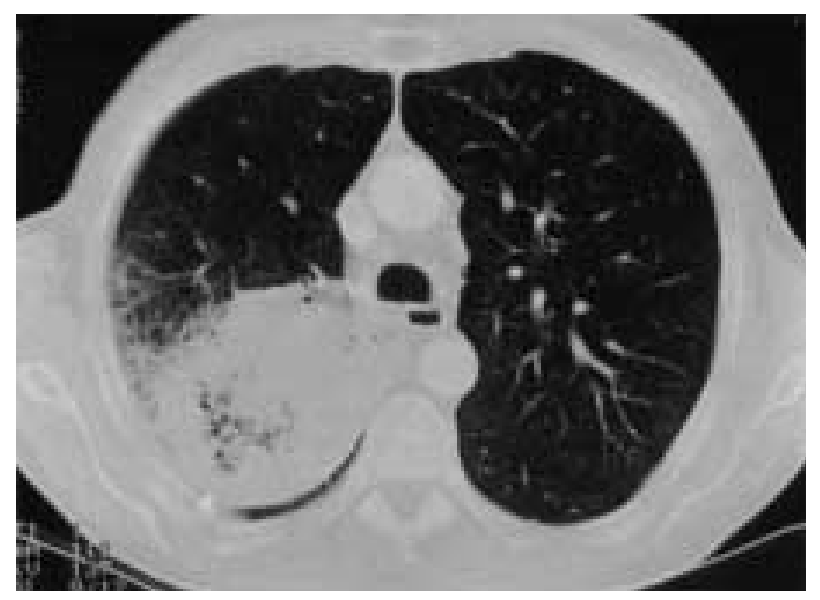

Fig. 6. - Isolated lobar consolidation with bulging of major fissure and cystic air spaces.

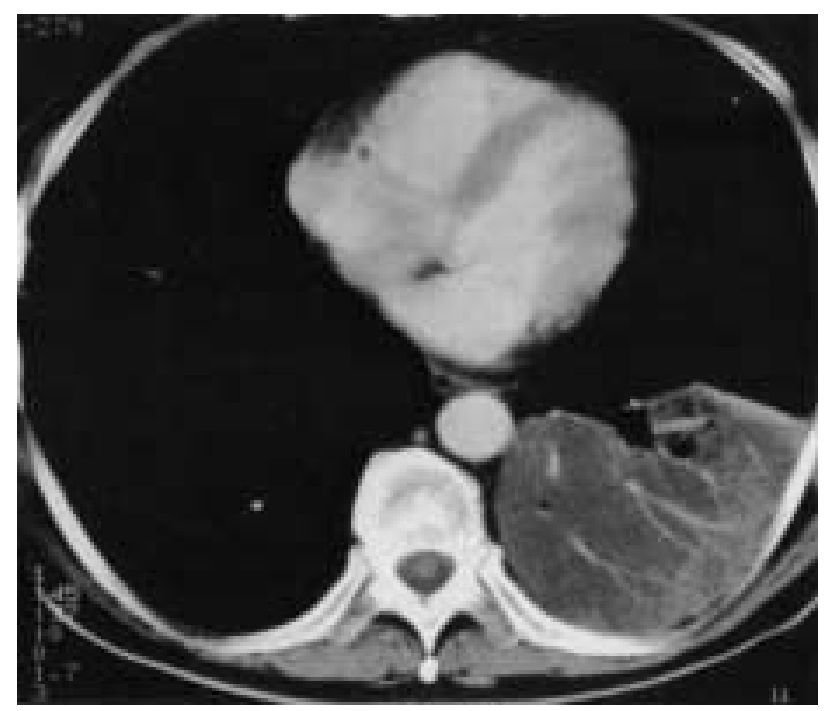

Fig. 7. - Isolated lobar consolidation with the angiogram sign.

Underlying evidence of pulmonary injury was found in 2 of the 42 patients: one case of pneumoconiosis and one case of usual interstitial pneumonia.

\section{Discussion}

Bronchioalveolar carcinoma is a distinct variant of lung cancer, accounting for up to $9 \%$ of all primary lung cancers $[19,25,26]$. BARSKY et al. [20] reported an increasing incidence of BAC, rising from $<5$ to $24 \%$ in successive 5 year periods from 1975 to 1990 ; much of this increase occurring in women $[27,28]$. BAC have a wide variety

Table 2. - Typical findings of lobar and diffuse consolidations

$\begin{array}{lr}\text { Cystic air spaces } & 19 / 23 \\ \text { Peripheral location } & 13 / 23 \\ \text { Air bronchogram } & 9 / 23 \\ \text { Fissural bulging } & 8 / 23 \\ \text { Angiogram sign } & 7 / 23 \\ \text { Nodes } & 6 / 23 \\ \text { Pleural effusion } & 1 / 23\end{array}$

of radiological manifestations, ranging from a single solid or cavitated nodule to multilobar consolidations [21, 22]. The multifocal nature of BAC, seen in 16 of out 42 cases, remains a major feature of this disease; the recognition of multifocality dates back to the description of the disease by MALASSEZ [29] in 1876, and has been traditionally explained as evidence for intrapulmonary metastasis: the so-called lymphatic-intra-alveolar spread-aerosol aspiration hypothesis [11]. Another explanation for multifocality is a multiple-clone hypothesis [30]. Evidence exists in our series (fig. 1), as well as in the literature [21], that a continuum exists between the solitary nodule, the lobar consolidation, and the diffuse forms.

The aggressiveness of BAC is quite variable: the present study suggests that the localized nodular lesions may be the early stage of a very indolent tumour that may infiltrate locally for a period of months, before becoming diffuse. Thus, prognosis differs markedly depending upon the radiological pattern. A nodule less than $3 \mathrm{~cm}$ in diameter may be cured by surgery in over $70 \%$ of patients [30-33], whereas death usually occurs in less than 3 yrs in the presence of diffuse disease [21]. A lobar consolidation has, theoretically, a somewhat better prognosis than does diffuse disease; however, experience with patients in this series agrees with the findings of Epstein et al. [3] and HiLl [21], who have noted that the prognosis of BAC presenting as a localized area of consolidation is poor. CT can distinguish between the diffuse and the localized forms, with subsequent prognostic implications [34]. Although CT is superior to radiography in the detection of diffuse nodules, the sensitivity of CT in showing pathologically proven multicentricity is only 63-68\% [35]. BAC, like other adenocarcinomas, may arise in damaged lung, but we found signs of previous lung injury in only two patients: one case of pneumoconiosis, and one case of usual interstitial pneumonia.

In our series, the major pattern of BAC (16 out of 42) was an isolated nodule or mass, with a size ranging 2-9 $\mathrm{cm}$. Eleven of the 16 were peripheral, seven had spiculated margins, and eight had pleural tags. Histopathological correlations have shown that spicules and pleural tags may be due to infiltrative tumour growth, lymphangitic spread, or desmoplastic reaction $[7,10,12,19$, $21,23,36]$. The differential diagnosis of peripheral tumours with pleural tags (fig. 2) and spiculated margins has to be made with other forms of adenocarcinoma, adenosquamous carcinoma [37], squamous cell carcinoma [23] and infectious nodules due to atypical mycobacteria [38]. Another reported sign seen in the nodular form of $\mathrm{BAC}$ is the presence of bubblelike lucencies inside the nodule [7, 23], but these were visible in only three of our cases (fig. 3). These bubblelike lucencies are related to the distinctive propensity of the tumour to proliferate along the alveolar walls without disrupting the overall lung architecture: these pseudocavitations, thus, correspond to patent small bronchi or air-containing spaces. True cavitation in BAC is unusual ( 1 in 16 in our series) because of the relative lack of necrosis and the preservation of normal lung architecture and perfusion to the involved lung. The differential diagnosis includes 
Wegener's disease, other forms of adenocarcinoma, squamous cell carcinoma, solitary metastasis or abscess; however, in all these cases, a true cavitation is generally observed pathologically.

Consolidations were found in 23 of the 42 patients. A peripheral distribution of the consolidation was observed in 13 of these 23 cases. The combination of the tumoral growth along the alveolar walls without destruction of the underlying architecture, and the secretion of mucin by the tumour, seen with various degrees in $80 \%$ of BAC [39], explains the combination of air bronchogram [19] and cystic air spaces (fig. 6). The differential diagnosis includes pneumonia, lymphoma, and bronchiolitis obliterans organizing pneumonia [40]. In our series, cystic airspaces combined with air bronchogram was frequent (19 of 23 patients). The production of mucin by the tumour [39] can cause swelling of the involved lobe, leading to bulging of the interlobar fissures (fig. 6). This was observed in 8 of the 23 patients. The differential diagnosis includes acute pneumonia, particularly Klebsiella pneumoniae pneumonia.

The angiogram sign [24] (fig. 7) has recently been described as a CT sign of BAC. It is supposed to be due to two factors: 1) the vascular tree, like the bronchial tree, is not distorted by tumour; and 2) due to mucin production, the consolidated lung has a lower attenuation than the vessels. Consequently, the vessels are clearly visible, particularly after intravenous administration of contrast material. This sign is suggestive but not specific for BAC, since it may be observed in many lesions, including lipoid pneumonia, alveolar haemorrhage, hydrocarbon inhalation, alveolar proteinosis, obstructive pneumonia [41], and lymphoma [42]. This sign was observed in 7 of the 23 patients in our series (table 2 ).

The extensive multinodular form of BAC is reported as the most infrequent pattern. It was only seen in three patients in our series, in accordance with the literature [22]. In one patient, some nodules were calcified (fig. 4); and in another, some nodules were cavitated (fig. 5). The differential diagnosis of such forms includes metastasis, histiocytosis $\mathrm{X}$, haematogenous abscesses, invasive aspergillosis and granulomatous diseases.

In summary, BAC has a wide spectrum of CT appearances, ranging from the isolated nodule to the multilobar consolidation. The peripheral location of the tumour is characteristic of the nodular as well as of the consolidated form. The differential diagnosis includes firstly the other forms of adenocarcinoma for the nodular form, and bronchiolitis obliterans organizing pneumonia for the consolidated form. Combination, of signs may be suggestive, for example a peripheral consolidation combining cystic airspaces and air bronchogram, fissural bulging and an angiogram sign. CT has a role in the diagnosis of diffuse versus localized forms, with subsequent therapeutic and prognostic implications.

\section{References}

1. Clagett OT, Allen TH, Payne WS, Woolner LB. The surgical treatment of pulmonary neoplasms: a 10 year experience. J Thorac Cardiovasc Surg 1964; 48: 391-400.
2. Arany LS. Bronchiolar (alveolar cell) carcinoma, failure to cause symptoms for more than twelve years. Am Rev Tuberc 1958; 78: 632-636.

3. Epstein DM, Gefter WB, Miller WT. Lobar bronchioloalveolar cell carcinoma. Am J Roentgenol 1982; 139: 463-468.

4. Liebow AA. Bronchioloalveolar carcinoma. Adv Int Med 1960; 10: 329-358.

5. Marcq M, Galy P. Bronchioloalveolar carcinoma: clinicopathologic relationships, natural history and prognosis in 29 cases. Am Rev Respir Dis 1973; 107: 621-629.

6. Schraufnagel D, Peloquin A, Pare JAP, Wang N. Differentiating bronchioloalveolar carcinoma from adenocarcinoma. Am Rev Respir Dis 1982; 125: 74-79.

7. Berkmen YM. The many faces of bronchioloalveolar carcinoma. Semin Roentgenol 1977; 12: 207-214.

8. Miller WT, Husted J, Firman D, Atkinson B, Pietra G. Bronchioloalveolar carcinoma: two clinical entities with one pathologic diagnosis. Am J Roentgenol 1978; 130: 905-912.

9. World Health Organization. World Health Organization histologic typing of lung tumors: second edition. Am J Clin Pathol 1982; 77: 123-136.

10. Steinbächer M, Van Kaick G, Schaaf J, Vollhaber HH. Computed tomographic and radiologic findings in alveolar cell carcinoma of the lung. Röfo 1985; 142: 267269.

11. Kuhlman JE, Fishman EK, Kuhajda FP, et al. Solitary bronchioloalveolar carcinoma: CT criteria. Radiology 1988; 167: 379-382.

12. Barsky SH, Huang S, Bhuta S. The extracellular matrix of pulmonary scar carcinomas is suggestive of a desmoplastic origin. Am J Pathol 1986; 124: 412-419.

13. Axiotis CA, Jennings TA. Observations of bronchioloalveolar carcinomas with special emphasis on localized lesions. Am J Surg Pathol 1988; 12: 918-931.

14. Ohori NP, Yousem SA, Griffin J, et al. Comparison of extracellular matrix antigens in subtypes of bronchioloalveolar carcinoma and conventional pulmonary adenocarcinoma: an immunohistochemical study. Am J Surg Pathol 1992; 16: 675-686.

15. Storey CF, Knudtson KP, Lawrence BJ. Bronchiolar ("alveolar cell") carcinoma of the lung. J Thorac Surg 1953; 26: 331-403.

16. Osann KE, Lung cancer in women: the importance of smoking, family history of cancer and medical history of respiratory disease. Cancer Res 1991; 51: 4893-4897.

17. Falk RT, Pickle LW, Fontham ETH, et al. Epidemiology of bronchioloalveolar carcinoma. Can Epidem Biomark Prev 1992; 1: 339-344.

18. Watson WL, Farpour A. Terminal bronchiolar or alveolar cell cancer of the lung: two hundred and sixty five cases. Cancer 1966; 19: 776-780.

19. Shapiro R, Wilson GL, Yesner R, Shuman H. A useful roentgen sign in the diagnosis of localized bronchioloalveolar carcinoma. Am J Roentgenol 1971; 114: 516-524.

20. Barsky SH, Cameron R, Osann KE, Tomita D, Holmes EC. Rising incidence of bronchioloalveolar lung carcinoma and its unique clinicopathologic features. Cancer 1994; 73: 1163-1170.

21. Hill CA. Bronchioloalveolar carcinoma: a review. Radiology 1984; 150: 15-20.

22. Adler B, Padley S, Miller RR, Müller NL. High-resolution CT of bronchioloalveolar carcinoma. Am J Roentgenol 1992; 159: 275-277.

23. Zwirewich CV, Vedal S, Miller RR, Müller NL. Solitary 
pulmonary nodule: high-resolution CT and radiologicpathologic correlation. Radiology 1991; 179: 469476.

24. Im Jung-Gi, Han MC, Yu EJ, et al. Lobar bronchioloalveolar carcinoma: "angiogram sign" on CT scans. Radiology 1990; 176: 749-753.

25. Edgerton R, Rao U, Takita H, Vincent RG. Bronchioloalveolar carcinoma: a clinical overview and bibliography. Oncology 1981; 38: 269-273.

26. Edward CW. Alveolar carcinoma: a review. Thorax 1984; 39: 166-174.

27. Ikeda $\mathrm{T}$, Kurita $\mathrm{Y}$, Inutsuka $\mathrm{S}$, et al. The changing pattern of lung cancer by histological type: a review of 1,151 cases from a university hospital in Japan, 19701989. Lung Cancer 1991; 7: 157-164.

28. Auerbach $\mathrm{O}$, Garfinkel L. The changing pattern of lung carcinoma. Cancer 1991; 68: 1973-1977.

29. Malassez L. Examen histologique d'un cas de cancer encephaloïde du poumon (épithélioma). Arch Physiol Normal Pathol 1876; 3: 353-372.

30. Barsky SH, Grossman D, Ho J, Holmes EC. The multifocality of bronchioloalveolar carcinoma (BAC): evidence and implications of a multiclonal origin. Mod Pathol 1992; 5: 112A (Abstract).

31. Belgrad R, Good CA, Woolner LB. Alveolar-cell carcinoma (terminal bronchiolar carcinoma): a study of surgically excised tumors with special emphasis on localized lesions. Radiology 1962; 79: 789-798.

32. Munnell ER, Lawson RC, Keller DF. Solitary bronchiolar (alveolar cell) carcinoma of the lung. J Thorac Cardiovasc Surg 1966; 52: 261-270.

33. Jackman RJ, Good CA, Clagett OT, Woolner LB. Survival rates in peripheral bronchogenic carcinomas up to four centimeters in diameter presenting as solitary pulmonary nodules. J Thorac Cardiovasc Surg 1969; 57: 1-8.

34. Metzger RA, Mulhern CB, Arger PH, Coleman BG, Epstein DM, Gefter WB. CT differentiation of solitary from diffuse bronchioloalveolar carcinoma. J Comput Assist Tomogr 1981; 5: 830-833.

35. Zwirewich CV, Miller RR, Müller NL. Multicentric adenocarcinoma of the lung: CT-pathologic correlation. Radiology 1990; 176: 185-190.

36. Gevenois PA, Koob M-C, Jacobovitz D, De Vuyst P, Yernault J-C, Struyven J. Whole lung sections for computed tomographic-pathologic correlations. Invest Radiol 1993; 28: 242-246.

37. Kazerooni EA, Bhalla M, Shepard J-A O, McLoud TC. Adenosquamous carcinoma of the lung: radiologic appearance. Am J Roentgenol 1994; 163: 301-306.

38. Moore EH. Atypical mycobacterial infection of the lung: CT appearance. Radiology 1993; 187: 777-782.

39. Thurlbeck WM. In: Pathology of the Lung. New York, Thieme, 1988; pp. 345-346.

40. Colby TV, Myers JL. Clinical and histologic spectrum of bronchiolitis obliterans, including bronchiolitis obliterans organizing pneumonia. Semin Respir Med 1992; 13: 119-133.

41. Murayama S, Onitsuka H, Murakami J, Torii Y, Masuda $\mathrm{K}$, Nishihara K. "CT angiogram sign" in obstructive pneumonitis and pneumonia. J Comput Assist Tomogr 1993; 17: 609-612.

42. Vincent JM, Ng YY, Norton AJ, Armstrong P. CT "angiogram sign" in primary pulmonary lymphoma. $J$ Comput Assist Tomogr 1992; 16: 829-831. 